\title{
ESCARIFICAÇÃO MECÂNICA E BIOLÓGICA PARA A REDUÇÃO DA COMPACTAÇÃO EM ARGISSOLO FRANCO-ARE NOSO SOB PLANTIO DIRETO(1)
}

\author{
S. L. ABREU(2), J . M. REICHERT(3) \& D. J . REINERT(3)
}

\begin{abstract}
RESUMO
O manejo influi nas propriedades físicas no campo, alterando a dinâmica do ar, da água e de solutos no solo. Propriedades físicas em sistemas de manejo conservacionista do solo foram avaliadas em um Argissolo Vermelho-Amarelo distrófico arênico (Typic Hapludalf) de textura franco-arenosa no horizonte A. Os tratamentos for am estabelecidos em solo com histórico de 10 anos de plantio direto, a saber: soja em sistema plantio di reto; soja em solo escarificado; crotalária em cultivo mínimo e solo descoberto sem preparo. Foram determinadas: a resistência mecânica à penetração; a densidade do solo; a porosidade total; a distribuição do tamanho de poros; a condutividade hidráulica do solo saturado e não saturado; a infiltração de água no solo pelos métodos de anéis concêntricos e sob chuva natural; a variação da umi dade volumétrica do solo durante o ciclo das culturas e a curva característica deágua no solo. Observou-se que a resistência mecânica à penetração (RP) foi máxima na camada de $0,075 \mathrm{~m}$, nos tratamentos sem preparo do solo, enquanto, no solo escarificado (Esc-soja), a RP máxima ocorreu em maior profundidade $(0,175 \mathrm{~m})$. A mobilização subsuperficial (escarificação) e a superficial (discagem e semeadura) do solo não se refletiram em redução na densidade do solo (Ds). O solo sob plantio direto de soja apresentou maior volume de macroporos que o solo sob cultivo de crotalária e descoberto, na profundidade 0,02 a $0,05 \mathrm{~m}$, favorecendo a maior condutividade hidráulica do solo saturado e a menor retenção de água no solo em situação de déficit hídrico. Dentre as propriedades físico-mecânicas analisadas, a RP mostrou-se mais sensível em detectar a compactação do que a Ds e porosidades, especialmente para camadas de solo pouco espessas. A eficácia da ruptura da camada compactada do solo depende da propriedade hídrica ou mecânica do solo usada como indicadora. Usando a condutividade hidráulica do solo saturado, em médio prazo, a "escarificação biológica" (CM-crot) mostrou-se mais eficaz na ruptura
\end{abstract}

(1) Trabal ho extraído da Tese de Mestrado do primeiro autor, apresentada ao Programa de Pós-Gradução em Agronomia da Universidade Federal de Santa Maria - UFSM. Financiado parcialmente por Pronex. Recebido para publicação em fevereiro de 2002 e aprovado em abril de 2004.

(2) Professor do Curso de Agronomia, Centro Universitário Luterano de J i-Paraná, Universidade Luterana do Brasil - CEULJ IULBRA. Av. Universitária, 762. CEP 78961-970. J i-Paraná (RO). E-mail: silvano@inf.ulbrajp.com.br

(3) Professor titular Departamento de Solos, Universidade Federal de Santa Maria - UFSM. CEP 97105-900 Santa Maria (RS). Bolsista Pesquisa CNPq. E-mail: reichert@ccr.ufsm.br 
da camada compactada e estabelecimento de poros condutores de água do que a escarificação mecânica (E sc-soja) do solo. Em contrapartida, se o indicador for a RP, o resultado é inverso. Assim, a propriedade hídrica ou mecânica do solo a ser usada como indicadora para a avaliação da eficácia da ruptura da camada compactada do solo depende do processo físico priorizado: a infiltração e redistribuição de água ou a penetração e crescimento de raízes.

Termos de indexação: compactação do solo, resistência à penetração, escarificação em plantio direto, plantas de cobertura.

\title{
SUMMARY: MECHANICAL AND BIOLOGICAL CHISELING TO REDUCE COMPACTION OF A SANDY LOAM ALFISOL UNDER NO- TILLAGE
}

\begin{abstract}
Soil management alters the physical soil properties and changes the soil air, water, and solutedynamics. Physical soil properties as affected by conservationist soil management systems werestudied in a sandy loam Typic Hapludalf. Thetreatments wereestabl ished on a soil that has been under no-tillage for 10 years, and consisted of: no-tillage soybeans, chise tillagesoybeans, reduced tillageCrotalaria, and baresoil without tillage Theevaluated soil properties weresoil penetration resistance, bulk density, porosity, poresizedistribution, saturated and unsaturated hydraulic conductivity, water infil tration using concentric rings or natural rainfall, variation of thevol umetric soil moisturethroughout the cropping cycle, and water retention curve. Soil penetration resistance (PR) was highest at $0.075 \mathrm{~m}$ and $0.175 \mathrm{~m}$ depth in no-tillage and chiseled soil, respectively. Soil subsurface mobilization with chiseling and surface mobilization due to disking and sowing did not influence the bulk density (BD) after the crop harvest. No-till soil under soybean crop had greater macropor osity than reduced tillagecrotal aria and baresoil at 0.02 to $0.05 \mathrm{~m}$ depth, resulting in a greater saturated hydraulic conductivity and lower water retention during periods of I ow water availability. Among theanalyzed soil physical-mechanical properties, PR seemed to bemoresensitiveto detect soil compaction than BD or porosities, particularly for thinner soil layers. The effectiveness in rupturing compacted soil depended on the hydraulic or mechanical soil property used as indicator. When using $\mathrm{K}_{(\theta \mathrm{S})}$ as indicator, in the medium term (4.5 months), "biological chiseling" by Crotalaria roots was more efficient at ameliorating soil compaction and establishing a network of conductive pores compared to mechanical chiseling. However, inverseresults wereobserved when PR was used as indicator. Thus, the choice of a soil physical property as indicator to evaluate the effectiveness of compaction reduction depends on which physical process is considered more important: water infiltration and redistribution or root penetration and growth.
\end{abstract}

Index terms: soil compaction, penetration resistance, chiseling in no-tillage, cover crops.

\section{NTRODUÇÃO}

A dinâmica da água no solo é dependente de características internas do solo (textura, porosidade, profundidadedolençol freático, tipo deargilominerais, matéria orgânica, dentre outras), externas (cobertura do solo e densidade de plantas, precipitação, temperatura) e da relação solo-planta-atmosfera (Musy \& Soutter, 1991).

As três principais propriedades da água que determinam a quantidade e o movimento da água no sol o são o potencial matricial, o teor de água e as funções de condutividade hidráulica do solo. O conhecimento das propriedades físico-hídricas do solo é fundamental para entender-se o processo dinâmico dos movimentos deágua edesolutos nosolo. As variáveis mais usadas para descrever o fluxo de água no solo incluem a taxa de infiltração, a condutividade hidráulica e o teor e a tensão de água no solo (Wang et al., 1998). A relação existente entre o teor deágua e a energia de retenção caracteriza a curva de retenção de água no solo. Essa relação é uma propriedade fundamental para descrever o processo dinâmico da água e de sol utos no sol o (Wang et al., 1998), bem como a disponi bilidade de água para as plantas.

As propriedades de transmissão de água no solo pelos macroporos podem exercer considerável influência na infiltração, drenagem e perdas de solo e de água por erosão, as quais afetam o desenvolvimento das culturas e a qualidade ambiental. A caracterização dessas propriedades é difícil e pode ser atribuída à frágil e transiente natureza dos macroporos do sol o eà falta detécnicas adequadas de medições (M essing \& J arvis, 1993). 
A influência das práticas culturais na compactação do solo foi estudada por Saxon et al. (1988). Eles verificaram que, em solos de textura franco-siltosa mecanizados superficialmente todos os anos e que passavam por ciclos de congel amento, as práticas culturais modificam a densidade do solo e, conseqüentemente, a infiltração de água, especialmente nas áreas com intensa mecanização, causando impacto negativo nas condições físicas e nos processos químicos e biológicos do solo.

O crescimento de raízes e o desenvol vimento e a produção das culturas são influenciados pelo nível de compactação do solo, dependendo do sistema de manejo utilizado (Fernandes et al., 1983; Silva et al., 2000a,b). Esses autores também encontraram efeito do sistema de preparo convencional, cultivo mínimoe plantio diretona densidade dosolo. Dentre os sistemas estudados, observaram que o sistema plantio direto apresentou uma distribuição de poros mais uniforme com a profundidade, refletindo a melhor estruturação natural do solo.

Para Håkansson et al. (1988), de maneira geral, o sistema de preparo convencional do solo tem ocasionado compactação subsuperficial em virtude da mobilização e descompactação mecânica da camada mobilizada, ao mesmo tempo que a carga aplicada apresenta efeito acumulativo em subsuperfície ao longo dos anos, ao passo que, em sistema plantio direto, a compactação é mais superficial pela não-mobilização do solo e concentração das cargas, acumulativas ao longo dos anos, na camada superficial dos solos.

A porosidade está relacionada com o manejo do solo, tais como: práticas de mecanização, tipo de cultura plantada, tipo de solo, biologia e macroestrutura do solo (Reynol ds et al., 1994; Azooz \& Arshad, 1996; Gimenez et al., 1997; Silva et al., 2000a,b,c).

Assim como para outras características físicas, a mecanização influencia as propriedades relacionadas com o fluxo de água no solo. U ma vez alteradas a porosidade e a densidade do solo, as propriedades associadas à condutividade hidráulica também variam (Reynolds et al., 1994; Bagarello, 1997).

A escarificação é uma das alternativas recomendadas freqüentemente para reduzir a compactação dos sol os. Outra alternativa refere-se ao uso de plantas que tenham sistema radicular profundo e agressivo capaz de crescer em camadas de sol o compactado. Contudo, para as condições de solos arenosos não há um sistema que tenha sua eficiência comprovada (Cubilla et al., 2003).

Os objetivos deste trabalho foram identificar o efeito de sistemas de manejo em propriedades físicohídricas e mecânicas do solo e avaliar a ruptura de camadas compactadas, usando escarificação e plantas com sistema radicular agressivo.

\section{MATERIAL E MÉTODOS}

\section{Solo e tratamentos}

O experimento foi realizado no ano agrícola 1998/ 99 na área experimental do Departamento de Sol os, da Universidade F ederal de Santa Maria, Iocalizada na latitude de 29 이 ' S e longitude de $53 \circ 42$ ' W, em um Argissolo Vermelho-Amarelo distrófico arênico (E mbrapa, 1999) (Typic Hapludalf). A textura superficial (horizonte A) é franco-arenosa e a subsuperficial (horizonte $B_{t}$ ), franco-argilosa. $O$ relevo é suave ondulado.

O delineamento experimental foi em blocos ao acaso, com quatro tratamentos e quatro repetições, distribuídos em parcelas de 5 × $20 \mathrm{~m}\left(100 \mathrm{~m}^{2}\right)$. Os tratamentos consistiram de quatro sistemas de manejo: (a) plantio direto de soja (PD-soja); (b) soja em sol o escarificado (Esc-soja), à profundidademédia de $0,25 \mathrm{~m}$, realizada 8 dias antes da semeadura; o escarificador usado dispunha de cinco hastes (três na barra dianteira eduas na traseira) de forma reta e posição inclinada no chassi com espaçamento entre hastes de aproximadamente $0,40 \mathrm{~m}$ e largura de trabal ho em torno de 1,5 a 2,0 m; (c) cultivo mínimo de Crotalária (CM-crot) com semeadura a lanço da Crotal aria spectabilis na densidade aproximada de $60 \mathrm{~kg} \mathrm{ha}^{-1}$ de semente, seguida de uma gradagem leve, queatingiu, em média, 0,03 m de profundidade no sol o para a incorporação das sementes, e (d) solo descoberto sem preparo (SP-desc), mantido sem vegetação e sem preparo.

A limpeza inicial do sol o foi efetuada com enxada e, periodicamente, foram eliminadas manual mente as plantas espontâneas com auxílio de facas, evitando-se o revolvimento do solo. A variedade de soja usada foi a FT-Abyara, semeada com semeadora mecânica de disco, com densidade média de 400 mil sementes ha-1. Para esses tratamentos, foi realizada uma adubação com NPK 5-20-20, na dosagem de $200 \mathrm{~kg} \mathrm{ha}^{-1}$. O trator usado para o preparo do solo e semeadura tinha rodas estândar e potência de $75 \mathrm{CV}$ no motor, considerado leve para as operações agrícolas.

O sol o foi cultivado sob sistema plantio direto nos últimos dez anos. De 1991 a 1997, a cultura de verão foi omilho, enquanto, no inverno, diferentes plantas foram cultivadas, incluindo aveia, ervilhaca e tremoço.

\section{Propriedades físico-mecânicas do solo}

A resistência mecânica à penetração (RP) foi determinada ao final do ciclo da cultura da soja, no dia 08/04/1999, com cinco repetições por parcela, utilizando penetrógrafo SOI LCONTROL ${ }^{\circledR}$ SC-60, até $0,40 \mathrm{~m}$ de profundidade. Paralelamente, em cinco profundidades, foi determinada a umidade gravimétrica do solo. 
A densi dade do solo(Ds) foi cal culada pela relação entre a massa do solo seco em estufa a $105^{\circ} \mathrm{C}$ e volume da amostra. As amostras foram coletadas em cilindros de $0,03 \mathrm{~m}$ de altura por $0,05 \mathrm{~m}$ de diâmetro, nas camadas 0,02 a 0,05 m, 0,12 a 0,15 m e 0,35 a $0,38 \mathrm{~m}$.

A amostragem para Ds e determinação da RP foi realizada entre as linhas das culturas, nos tratamentos com plantas, evitando-se as linhas de tráfego dos equi pamentos usados, especial mente do tráfego do trator para a semeadura.

A porosidade total (Pt) foi obtida por duas formas de cálculo. A primeira baseou-se na umidade de saturação do solo e a segunda na relação da densidade do solo com a densidade das partículas do solo. Os val ores de densidade de partículas para as profundidades de 0,02 a $0,05 \mathrm{~m}, 0,12$ a $0,15 \mathrm{~m}$ e 0,35 a 0,38 m foram, respectivamente, de 2,62; 2,63 e $2,62 \mathrm{Mg} \mathrm{m}^{-3}$, quantificados pelo método do balão volumétrico (E mbrapa, 1997).

A distribuição de tamanho de poros foi cal culada a partir dos dados da curva característica de água no solo, descrita posteriormente neste artigo, utilizando a equação fundamental da capilaridade.

\section{Propriedades hídricas do solo}

A condutividade hidráulica do solo saturado $\left(\mathrm{K}_{(\theta \mathrm{s})}\right)$ foi determinada, no campo, no final do ciclo das culturas, na profundidade de 0,02 a 0,12 m, com duas repetições por parcela, pelo método do permeâmetro de Guel ph (Elrick et al., 1987), com carga hidráulica constante.

A condutividade hidráulica do sol o não saturado $\left(K_{(\theta)}\right)$ foi determinada no campo no final do ciclo das culturas, nas profundidades de $0 \mathrm{~m}$ (superfície) e a 0,12 m (subsuperfície), utilizando o método do infiltrômetro de tensão, com disco de placa porosa de $0,214 \mathrm{~m}$ de diâmetro, conforme método descrito por Reynolds (1993) e SOI L... (1991). Os cálculos deK $_{(\theta)}$ foram realizados com o auxílio de um software em linguagem FORTRAN ${ }^{\circledR}$ (Reynolds, 1995) e equações apresentadas por Reynolds (1993). As profundidades utilizadas foram estabelecidas com base no seguinte: (a) influência da condutividade hidráulica não saturada $\left(\mathrm{K}_{(\theta)}\right)$ da superfície do solo na permeabilidade do solo, e (b) presença de uma camada compactada localizada na profundidade de 0,10 a 0,15 m como conseqüência das práticas de mecanização real izadas nestesolo, sendo essa camada um fator limitante para o fluxo de água no solo.

A infiltração deágua no sol o foi determinada pelo método dos anéis concêntricos, no final do ciclo das culturas. A equação de Horton (Hillel, 1998) foi ajustada aos dados de taxas de infiltração no tempo.

A infiltração e o escoamento de água no sol o com chuva natural foram avaliados em uma mi croparcela $(0,50 \times 0,75 \mathrm{~m})$ delimitada por bordas metálicas de $0,10 \mathrm{~m}$ de altura, cravadas $0,05 \mathrm{~m}$ no solo. Na parte inferior do terreno e por meio de uma calha, foi coletada toda a água que escoou de dentro da microparcela. As determinações de infiltração por chuva natural foram realizadas durante o ciclo das culturas. Pela diferença entre a precipitaçãototal e o volume de água escoado, determinou-se a lâmina de água infiltrada no solo.

Para avaliar a precipitação, foram utilizados quatro pluviômetros instalados no experimento, tendo os valores correlacionados com os dados de precipitação da estação meteorológica da UFSM apresentado uma correl ação positiva com $r^{2}=0,854$.

O teor deágua no solo foi avaliado duranteo ciclo das culturas, nas profundidades de 0 a $0,10 \mathrm{~m}$ com TDR (reflectômetro de domínio de tempo) eaos 0,20, 0,35 , e $0,50 \mathrm{~m}$ de profundidade com sonda de nêutrons, num intervalo de dois a três dias entre determinações. Em cada avaliação, a umidade do solo foi medida em dois pontos por parcela com o TDR eem um tubo de acesso por parcel a com a sonda de nêutrons. A lâmina de água armazenada no solo foi calculada para profundidade de $0,60 \mathrm{~m}$, durante o cicl o das culturas, com os dados de teor vol umétrico deágua no solo. ComooTDR apresentou problemas, em vários dias não foi possível realizar leituras na profundidade de 0 a $0,10 \mathrm{~m}$, prejudicando a curva de variação do teor de água no solo para a profundidade em questão e, conseqüentemente, o cálculo da lâmina de água armazenada. Essa determinação integrou os val ores de teor volumétrico de água no solo nas diferentes profundidades de acordo com a área de abrangência dos equi pamentos utilizados.

A curva característica de água no solo foi determinada em amostras com estrutura não deformada, col etadas no final do ciclo das culturas, utilizando um cilindro de volume conhecido $\left(0,00589 \mathrm{~m}^{3}\right)$. As amostras foram coletadas nas profundidades de 0,02 a 0,05, 0,12 a 0,15 e 0,35 a $0,38 \mathrm{~m}$, sendo coletados dois anéis em cada profundidade por parcela. Depois de saturadas por $48 \mathrm{~h}$ e determinada a massa do solo saturado, as amostras foram levadas à mesa de tensão e submetidas às tensões de 1 e $6 \mathrm{kPa}$ emedi da a massa das amostras em cada tensão; seqüencialmente, foram transferidas para a câmara de Richards onde foram submetidas às tensões de 30, 100 e $500 \mathrm{kPa}$. Cessada a drenagem em cada tensão, foi determinada a massa da amostra. A equação de van Genuchten (1980) foi ajustada aos dados da curva característica da água no solo.

\section{Análise estatística}

A análise estatística constou de análise de variância e comparação de médias entre os tratamentos, pelo teste de DMS a $5 \%$ de erro, efetuada com o pacote estatístico SAS (SAS, 1985). As diferenças entre profundidades não foram analisadas estatisticamente. 


\section{RESULTADOS E DISCUSSÃO}

\section{Propriedades físico-mecânicas do solo}

A resistência mecânica à penetração (RP) (Figura 1a), nos teores de água considerados (Figura 1b), foi máxima na camada de $0,075 \mathrm{~m}$, nos tratamentos sem preparo do solo, atingindo valores máximos de $1600 \mathrm{kPa}$ noCM-crot, $1.450 \mathrm{kPa}$ noSPdesc e $1.350 \mathrm{kPa}$ no PD-soja. Contudo, no solo escarificado (Esc-soja), a RP máxima ocorreu em maior profundidade $(0,175 \mathrm{~m})$, possivelmente na camada não afetada pela mobilização do solo, atingindo $850 \mathrm{kPa}$. Nessa condição de umidade (Figura 1b), em nenhum dos tratamentos a RP superou olimite de $2.000 \mathrm{kPa}$ considerado por Taylor et al. (1966) crítico ao crescimento de raízes. Na comparação entre os tratamentos, contudo, houve diferenças significativas na RP somente a 0,025 m.

O maior estado de compactação observado na camada de 0,075 m nos tratamentos sem mobilização do solo deve-se ao efeito cumulativo de pressões de máquinas e implementos que o solo recebe e, ainda, à acomodação natural das partículas (Carvalho J únior et al., 1998). Na presença de tráfego, a reacomodação das partículas e agregados do solo podeser rápida, eapenas um evento de tráfego sobre o sol o pode provocar um aumento de resistência à penetração para níveis semel hantes ao que estava antes da escarificação (Silva et al., 2000c). O confinamento de maiores val ores de RP em camadas em torno de 0,10 m de profundidade, com amplitude de 0,075 a 0,170 m, parece ser uma característica de solos em plantio direto, tanto em solos mais arenosos (Silva et al., 2000c; Silva, 2003; Streck, 2003) quanto nos mais argil osos (GenroJ unior, 2002; Silva, 2003; Secco, 2003).
Os menores valores numéricos de RP até à profundidade de $0,15 \mathrm{~m}$ foram observados no solo escarificado (Esc-soja) (Figura 1a). Com a escarificação do solo, a mobilização deve ter reduzi do a coesão do sol o e, apesar de estar reconsolidado na época das determinações, a recomposição da coesão ainda deve ser pequena. Bradford (1986) destaca que os fatores de sol o que afetam a sua resistência à penetração são não somentea umidade ea densi dade do solo, mas também a estrutura e propriedades mecânicas do solo, como a compressibilidade e resistência ao cisal hamento do solo. Os parâmetros que descrevem o cisal hamento do sol o são o ângulo de atrito interno e a coesão, sendo essa afetada pel o estado de compactação do solo (Secco, 2003).

Em solo não mobilizado (PD-soja, CM-crot e SPdesc), a RP, na camada mais superficial $(0,025 \mathrm{~m})$, foi de 1,6 a 1,9 vez maior que na camada mais compactada $(0,075 \mathrm{~m})$, enquanto, no sol o mobilizado, esseincremento foi de 2,4 vezes (Figura 1a). Embora tais diferenças possam ser atribuídas à maior umidade (Figura 1b) na camada superficial, essa camada do solo é mobilizada por equipamentos e organismos vivos esofre adição de resíduos vegetais e incremento de matéria orgânica. Nesse sentido, segundo Genro J unior (2002), para culturas de inverno, por exemplo, o espaçamento médio usado é de 0,17 mea mobilização de uma camada de 0,05 m ou mais pel os mecanismos sul cadores para col ocação de semente e adubo, sendo $30 \%$ da área mobilizada em uma única operação. Considerando o efeito das culturas de verão e o cultivo sucessivo, em pouco tempo, toda a camada superficial dos solos sob plantio direto é mobilizada.

Contudo, contrariamente ao esperado, a mobilização subsuperficial e superficial do solo não se refletiu em redução na densidade do solo (Ds)

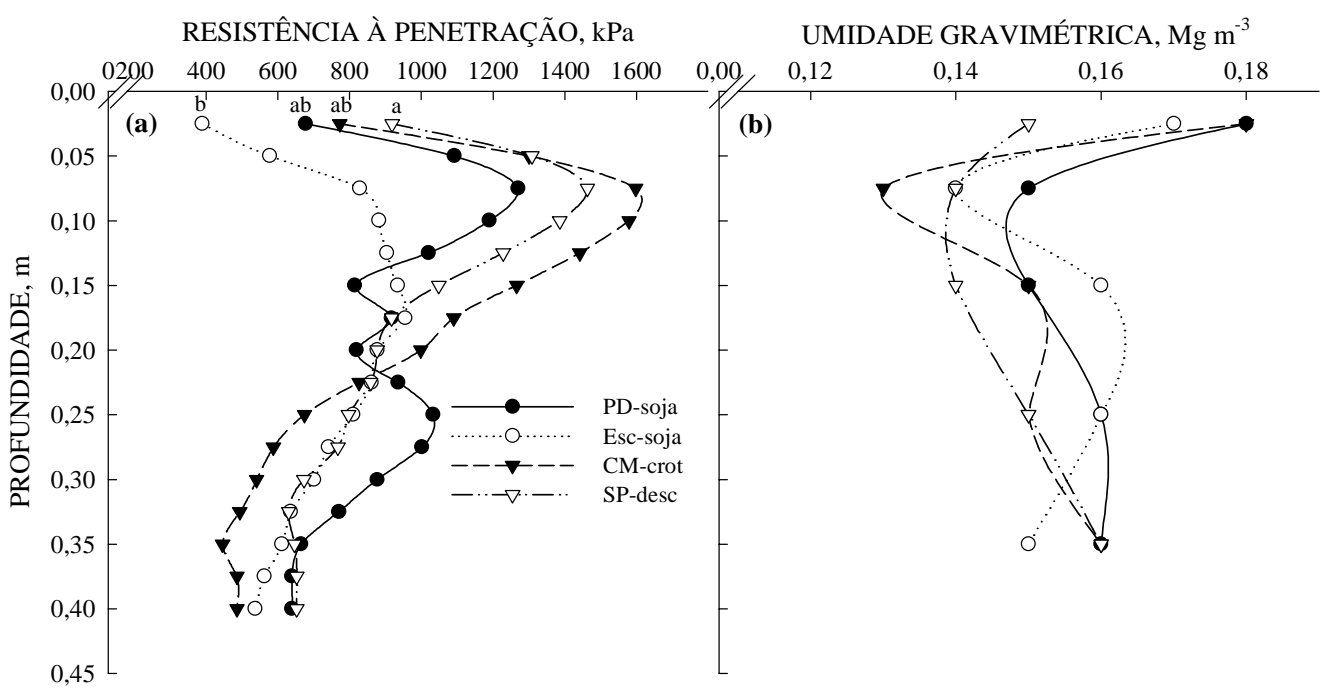

Figura 1. Resistência mecânica à penetração (a) e umidade gravimétrica (b) do solo na profundidade de 0-0,40 m em solo sob diferentes sistemas de manejo. 
(Quadro 1). Com pequenas diferenças numéricas (máximo 0,1 $\mathrm{Mg} \mathrm{m}^{-3}$ ), a Ds variou de 1,62 a $1,72 \mathrm{Mg} \mathrm{m}^{-3}$, na profundidade de 0,02 a $0,05 \mathrm{~m}$, de 1,63 a 1,68 $\mathrm{Mg} \mathrm{m}^{-3}$, na profundidade de 0,12 a $0,15 \mathrm{~m}$, e de 1,55 a 1,64 $\mathrm{Mg} \mathrm{m}^{-3}$, na profundidade de $0,35 \mathrm{a}$ $0,38 \mathrm{~m}$. O maior valor numérico deDs foi observado na profundidade de 0,12 a 0,15 m, nos tratamentos PD-soja e Esc-soja, e de 0,02 a 0,05 m, nos tratamentos CM-crot eSP-desc.

A semel hança do val or da Ds em sol o escarificado (E sc-soja) em relação ao sol o não mobilizado deveuse, possivel mente, ao processo de reconsol idação do solo, ocorrido no período de 4,5 meses entre a mecanização e a determinação da densi dade. Como a Ds foi sempre determinada no sol o entreas linhas das culturas, nos tratamentos com plantas, esse aumento na densidade do solo não foi devido ao tráfego de equi pamentos durante o estabel ecimento das culturas.

Os dados de distribuição de tamanho de poros, a macroporosidade e a porosidade encontram-se no quadro 1 e na figura 2. O PD-soja apresentou mais macroporos que o CM-crot e SP-desc, na profundidade 0,02 a 0,05 $\mathrm{m}$, em razão da possível maior quantidade de poros biológicos. Essa propriedade do espaço poroso do tratamento PD-soja explica outras propriedades, como a maior $\mathrm{K}_{(\theta s)}$ e a menor retenção deágua no solo em situação de déficit hídrico, discutidas posteriormente neste artigo. Apesar da diferença na macroporosidade, quando se consideraram os diferentes tamanhos de poros, só houve deferença entrePD-soja eCM-crot na classe de 148-24,8 $\mu \mathrm{m}$ (F igura 2).
$\mathrm{Na}$ profundidade de 0,12 a $0,15 \mathrm{~m}$, houve diferença na classe de poros com raio entre 24,8 e 4,51 e de 4,51 a 1,45 $\mu \mathrm{m}$, com maior quantidade de poros nas classes de raio de poros entre 24,8 e 4,51 um para o tratamento PD-soja em relação ao Esc-soja. O efeito da mobilização do solo sobre a macroporosidade no tratamento Esc-soja não persistiu até o momento da col eta do solo, graças à reconsol idação ocorrida em sol os mobilizados e que recebem sucessivos ciclos de umedecimento e secagem.

$\mathrm{Na}$ profundidade de 0,35 a $0,38 \mathrm{~m}$, não foi observada diferença entre os tratamentos, tampouco na distribuição do tamanho de poros como conseqüência dos tratamentos estudados, porém as classes de poros que predominam neste solo apresentaram poros de 148 a 4,4 e < 0,29 $\mu \mathrm{m}$.

Analisados integradamente, os resultados de resistência, densidade e porosidades demonstram, aparentemente, que a RP parece ser mais sensível na detectação da compactação do que a Ds e porosidades, especialmente para camadas pouco espessas, as quais caracterizam melhor a variação em propriedades mecânicas do solo. Esses resultados estão em consonância com os de Voorhees (1983), ao afirmar que a densidade do solo não é o fator mais limitante ao crescimento radicular, mas, sim, a resistência que o solo oferece ao crescimento das raízes, determinada por um penetrômetro. Contudo, nem sempre o limitante da produtividade das culturas é a resistência mecânica do solo, mas um conjunto de fatores, tais como: a própria resistência do solo à penetração de raízes, o espaço

Quadro 1. Densidade do solo (Ds), porosidade total (Pt), macroporosidade (Mac) e microporosidade (Mic) para três profundidades em solo sob diferentes sistemas de manejo

\begin{tabular}{|c|c|c|c|c|c|}
\hline Tratamento & Ds & $\mathbf{P t} \mathbf{t}^{(1)}$ & $\mathbf{P} \mathbf{t}^{(2)}$ & Mac & Mic \\
\hline & $\mathrm{Mg} \mathrm{m}^{-3}$ & 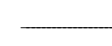 & - & 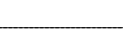 & + \\
\hline & \multicolumn{5}{|c|}{ Profundidade de 0,02 a $0,05 \mathrm{~m}$} \\
\hline PD-soja & $1,62 \mathrm{a}$ & $0,38 \mathrm{a}$ & 0,38 & 0,13 a & 0,25 \\
\hline Esc-soja & $1,62 \mathrm{a}$ & $0,40 a$ & 0,38 & $0,12 a b$ & 0,26 \\
\hline CM-crot & $1,72 \mathrm{a}$ & $0,37 \mathrm{a}$ & 0,37 & $0,10 \mathrm{~b}$ & 0,27 \\
\hline \multirow[t]{2}{*}{ SP-desc } & $1,66 \mathrm{a}$ & $0,39 a$ & 0,38 & $0,10 \mathrm{~b}$ & 0,27 \\
\hline & \multicolumn{5}{|c|}{ Profundidade de 0,12 to $0,15 \mathrm{~m}$} \\
\hline PD-soja & $1,64 \mathrm{a}$ & $0,39 a$ & 0,38 & $0,12 \mathrm{a}$ & 0,26 \\
\hline Esc-soja & $1,68 \mathrm{a}$ & $0,38 a$ & 0,38 & $0,12 a$ & 0,26 \\
\hline CM-crot & 1,65 a & $0,39 a$ & 0,39 & $0,12 \mathrm{a}$ & 0,27 \\
\hline \multirow[t]{2}{*}{ SP-desc } & $1,63 \mathrm{a}$ & $0,39 a$ & 0,38 & $0,12 \mathrm{a}$ & 0,26 \\
\hline & \multicolumn{5}{|c|}{ Profundidade de 0,35 a $0,38 \mathrm{~m}$} \\
\hline PD-soja & $1,64 \mathrm{a}$ & $0,39 a$ & 0,39 & $0,11 \mathrm{a}$ & 0,28 \\
\hline Esc-soja & $1,55 \mathrm{a}$ & $0,40 a$ & 0,40 & $0,15 a$ & 0,25 \\
\hline CM-crot & $1,59 \mathrm{a}$ & $0,39 a$ & 0,40 & $0,14 a$ & 0,26 \\
\hline SP-desc & $1,59 \mathrm{a}$ & $0,40 a$ & 0,40 & $0,12 \mathrm{a}$ & 0,28 \\
\hline
\end{tabular}

(1) Calculado pela umidade de saturação do solo. ${ }^{(2)}$ Calculado pela densidade de partícula.

Médias para cada profundidade, seguidas pela mesma letra não diferem estatisticamente pelo teste DMS a $5 \%$ de probabilidade de erro. 


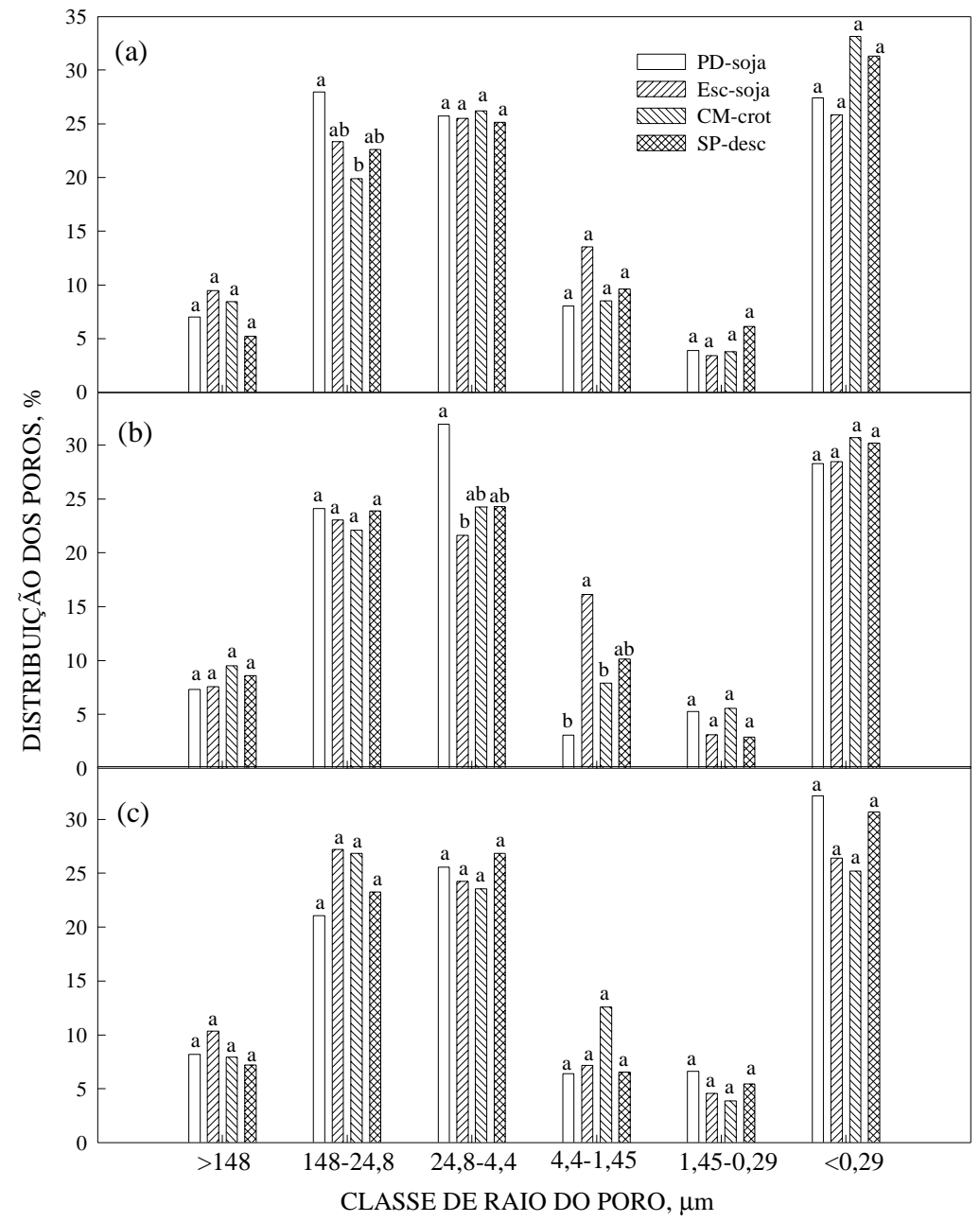

Figura 2. Distri buição de tamanhos de poros (fração relativa da porosidade total) para as profundidades de 0,02 a 0,05, 0,12 a 0,15 e 0,35 a 0,38 $\mathrm{m}$ em solo sob diferentes sistemas de manejo. Médias seguidas de mesma letra não diferem estatisticamente entre si pelo teste DMS a $5 \%$ de erro.

aéreo destinado às trocas gasosas ea quantidade de água disponível para as plantas (Letey, 1985; da Silva et al., 1994; Tormena et al., 1998; Silva, 2003).

\section{Propriedades hídricas do solo}

A condutividade hidráulica do solo saturado $\left(\mathrm{K}_{(\theta \mathrm{s})}\right)$, determinada no campo com permeâmetro de Guel ph, na profundidade de 0,02 a 0,12 m (Figura 3), apresentou coeficiente de variação relativamente alto $(52,8 \%)$, reduzindo a possibilidade de diferenças estatísticas entre os tratamentos. Resultados de Tsegaye \& Hill (1998) e Warrick \& Nielsen (1980) indicam quea variabilidade da $\mathrm{K}_{(\theta \mathrm{s})}$ é normal mente alta, podendo chegar a valores de CV de $190 \%$.

As maiores $K_{(\theta s)}$ do sol o foram observadas no sol o com cultivo mínimo de crotalária (CM-crot) e com plantio direto de soja (PD-soja). Este, entretanto, não diferiu dos demais tratamentos (Figura 3). A formação e a manutenção de macroporos verticais ao longo do perfil, decorrentes da decomposição das raízes de culturas anteriores no sol o sem preparo, e a agressividade do sistema radicular da crotalária, penetrando na camada subsuperficial do solo e constituindo um meio poroso mais contínuo, devem ter contribuído para o aumento na $\mathrm{K}_{(\theta \mathrm{s})}$.

Tais resultados estão em consonância com os de Cubilla et al. (2002) e GenroJ unior (2002). Cubilla et al. (2002), em solo franco-arenoso igual ao do presente estudo, não encontraram diferença significativa entre os valores de Ds para todos os tratamentos estudados ao final de três anos da sucessão/rotação de culturas envolvendo plantas de cobertura no inverno/milho/plantas de cobertura no verão, porém as plantas de cobertura criaram poros biológicos de alta funcionalidade na aeração e infiltração de água no solo. Como reflexo da funcionalidade do espaço poroso, Genro J unior (2002), em solo argiloso, observou tendência de aumento da condutividadehidráulica após a incl usão de guandu anão em esquemas de rotação de culturas com milho, soja e trigo. 


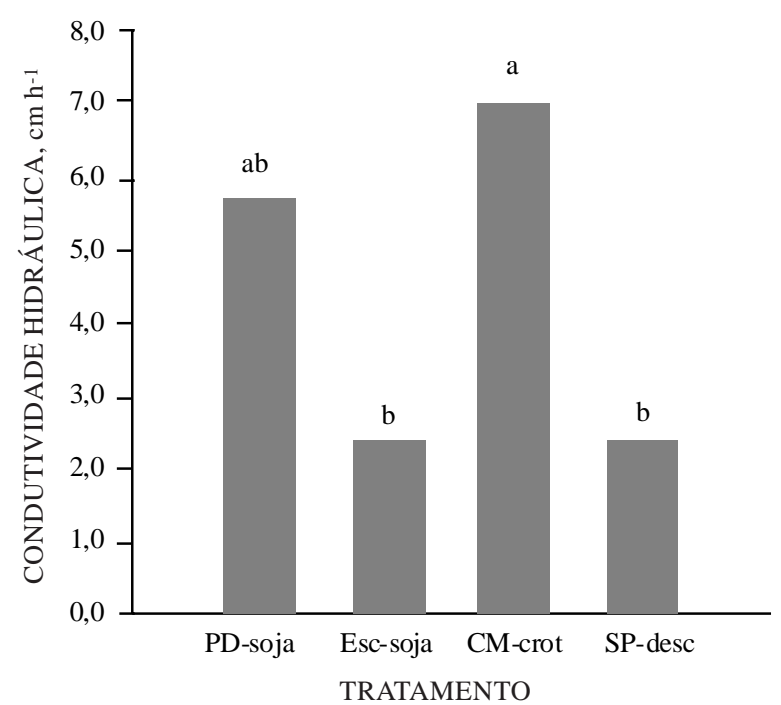

Figura 3. Condutividade hidráulica em solo saturado $\left(K_{(\theta s)}\right)$ determinada no campo na profundidade de 0,02 a 0,12 m, em solo sob diferentes sistemas de manejo. Médias seguidas de mesma letra não diferem estatisticamente entre si pelo teste DMS a $5 \%$ de erro.

Os val ores de $\mathrm{K}_{(\theta \mathrm{s})}(\mathrm{Figura} 3)$ foram semel hantes para cultivo de soja em sol o escarificado (E sc-soja) e em plantio direto (PD-soja) e solo descoberto sem preparo (SP-desc). I sso demonstra que 4,5 meses após a escarificação, essa não foi eficaz em aumentar a $\mathrm{K}_{(\theta \mathrm{s})}$ do solo. Nesse intervalo do tempo entre a escarificação e a determinação da condutividade, devem ter ocorrido reconsol idação do sol o e rearranjo do espaço poroso, tornando-o menos condutivo. Outrossim, o uso do escarificador possivelmente rompeu poros contínuos verticais com a mudança da estrutura do solo, diminuindo a $\mathrm{K}_{(\theta s)}$. Após qualquer mobilização do solo, o processo de reconsol idação é resultante da chuva e dos ciclos de umedecimento e secagem (Hillel, 1998), mesmo na ausência de tráfego (Schäfer et al., 2001).

Comparando os sistemas de ruptura da camada compactada e usando-se o indicador $\mathrm{K}_{(\theta \mathrm{s})}$ do solo, em médi o prazo, a "escarificação biológica" (CM-crot) foi mais eficaz na criação de poros condutores de água do que a escarificação mecânica (Esc-soja) do solo. Em contrapartida, se o indicador for a RP, o resultado é inverso. Assim, a propriedade hídrica ou mecânica do solo a ser empregada como indicadora na avaliação da eficácia da ruptura da camada compactada do solo depende do processo físico priorizado: a infiltração e redistribuição de água ou a penetração e crescimento de raízes.

A K $_{(\theta)}$ foi 1,2 vez (PD-soja) a 1,7 vez (SP-desc) numericamente maior na superfície do solo em relação à profundidade de 0,12 m (Figura 4), indicando não ser a camada compactada localizada abaixo dos $0,10 \mathrm{~m}$ de profundidade limitante somente à penetração de raízes (Figura 1 ) em solo mais seco, mas também ao fluxo de água do solo próximo à saturação (tensão média de 0,09 m). Nessa tensão, com base na equação da capilaridade, os poros de até 1,6 $\mathrm{mm}$ de raio são os atuantes no fluxo de água.

A variabilidade dos dados de $K_{(\theta)}$ foi inferior à observada para $\mathrm{K}_{(\theta \mathrm{s})}$. O CV para $\mathrm{K}_{(\theta)}$ foi em torno de $24 \%$, para ambas as profundidades, próximoao valor relatado por Perroux \& White (1988). O SP-desC apresentou o maior $\mathrm{K}_{(\theta)}$, sendo similar aos valores encontrados para CM-crot e Esc-soja. Na profundidade de 0,12 m, não se observaram diferenças significativas entre os tratamentos.

A taxa de infiltração deágua no solo, determinada pel o método de anéis concêntricos, não diferiu entre os tratamentos (Quadro 2 eFigura 5). Essefato pode ser atribuído parcialmente ao elevado CV (77\%) para a taxa constante de infiltração $\left(I_{c}\right)$ medida. Valores próximos a esses coeficientes foram relatados também por outros autores (Ankeny et al., 1990; Cooke et al., 1993). Foi observada, no entanto, tendência em superioridadenumérica tanto na taxa inicial de infiltração ( $\left.I_{0}\right)$ como no I c para os tratamentos PD-soja e Esc-soja em relação aos demais. As possíveis razões para esses valores na $\mathrm{I}_{0}$ podem ser atribuídos ao menor teor de água no solo no momento inicial da determinação em solo

Quadro 2. Taxa inicial ( $I_{\text {oestimada }}$ e $\left.I_{0 \text { medida }}\right)$ e taxa constante $\left(I_{c \text { estimada }}\right.$ e $\left.I_{c \text { medida }}\right)$ de infiltração de água em solo sob diferentes sistemas de cultivo

\begin{tabular}{|c|c|c|c|c|c|}
\hline \multirow{2}{*}{ Tratamento } & \multicolumn{2}{|c|}{ Io } & \multicolumn{2}{|c|}{ Ic } & \multirow{2}{*}{ I total ${ }^{(2}$} \\
\hline & Medida & Estimada 1 & Medida & Estimada(1) & \\
\hline & \multicolumn{4}{|c|}{$\mathrm{mm} \mathrm{h}^{-1}$} & $\mathrm{~mm}$ \\
\hline PD-soja & 48,46 & 77,31 & $7,81 \mathrm{a}$ & 9,52 a & 18,96 \\
\hline Esc-soja & 33,83 & 39,30 & $8,31 \mathrm{a}$ & 11,49 a & 14,11 \\
\hline CM-crot & 29,71 & 54,54 & $5,38 \mathrm{a}$ & 6,97 a & 9,95 \\
\hline SP-desc & 18,46 & 47,68 & $5,38 a$ & $6,54 a$ & 9,64 \\
\hline
\end{tabular}

${ }^{(1)}$ Estimada pela equação de Horton. ${ }^{(2)}$ Infiltração total até 90 min.

Médias seguidas de mesma letra não diferem estatisticamente entre si pelo teste DMS a 5\% de probabilidade de erro. 
com cultivo de soja, ao selamento superficial nos tratamentos CM-crot eSP-desc e ao rompimento de poros superficiais na gradagem efetuada no tratamento CM-crot. Para os valores de I ${ }_{C}$ é provável que o selamento superficial (CM-crot eSP-desc) eo rompimento de por os superficiais (CM-crot) tenham sido determinantes na tendência de redução do $\mathrm{I}_{\mathrm{C}}$.

A infiltração de água no solo sob chuva natural foi medida para treze eventos pluviais duranteo ciclo das culturas (Quadro 3). À medida que as culturas de soja e crotalária foram crescendo e cobrindo a superfície do solo, houve um acréscimo na diferença entre a lâmina escoada no tratamento SP-desc em relação aos demais tratamentos. Em eventos dealta precipitação, o efeito da cobertura do solo, proporcionando maior infiltração de água, foi mais evidente. No dia 167, o escoamento no SP-desc foi 5,8 vezes superior ao do tratamento E sc-soja e 9,7 vezes superior ao do CM-crot.

A lâmina escoada em relação ao total precipitado apresentou val ores el evados notratamento SP-desc, chegando a $39,5 \%$ para o dia 76 , enquanto o menor val or foi de $2,9 \%$ para o dia 59 . O tratamento PDsoja teve o maior escoamento de $6,8 \%$ no dia 82 e menor de 0,7 \% para uma precipitação de $120 \mathrm{~mm}$ no dia 157.

O teor deágua no sol oapresentou comportamento semel hante entre os tratamentos nas profundidades avaliadas, com maior diferença entre as épocas de amostragem na camada de 0,10 a 0,27 m (Figura 6). Esses dados concordam com os dados de densidade e porosidades que estão ligados à retenção de água no solo.

As diferenças no teor de água no solo entre as épocas de amostragem diminuíram com a profundidade do solo, com oscilações entre 0,18 e $0,32 \mathrm{~m}^{3} \mathrm{~m}^{-3}$ na profundidade de 0,43 a 0,60 m. Essa diminuição deveu-se à evaporação de água e absorção pelas raízes das plantas, as quais mostraram-se mais intensas nas camadas superficiais e diminuíram com a profundidade do solo.

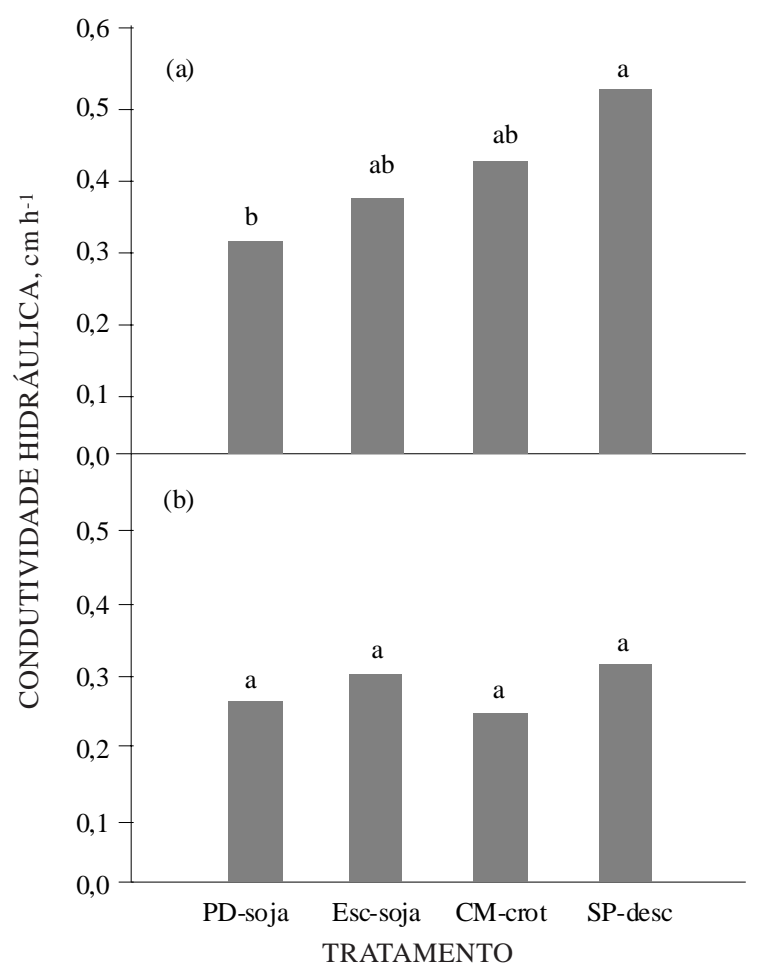

Figura 4. Condutividade hidráulica em solo não saturado $\left(K_{(\theta)}\right)$ na superfície (a) e a 0,12 $\mathrm{m}$ de profundidade (b) sob diferentes sistemas de manejo. Médias seguidas de mesma letra não diferem estatisticamente entre si pelo teste DMS a $5 \%$ de erro.

A lâmina de água armazenada no solo foi calculada para a profundidade de 0 a $0,60 \mathrm{~m}$ (Figura 7). Como os dados de umidade obtidos com o TDR apresentam fal has na leitura, calculou-se também a lâmina de água armazenada de 0,10 a $0,60 \mathrm{~m}$ com os dados obtidos somente com sonda de nêutrons. A lâmina de água armazenada ao longo do cicl o das culturas de verão apresentou tendência a maiores valores nos tratamentos PD-soja e CMcrot, apesar das grandes variações entre as épocas

Quadro 3. Lâmina escoada sob chuva natural e precipitação pluvial em solo sob diferentes sistemas de manejo

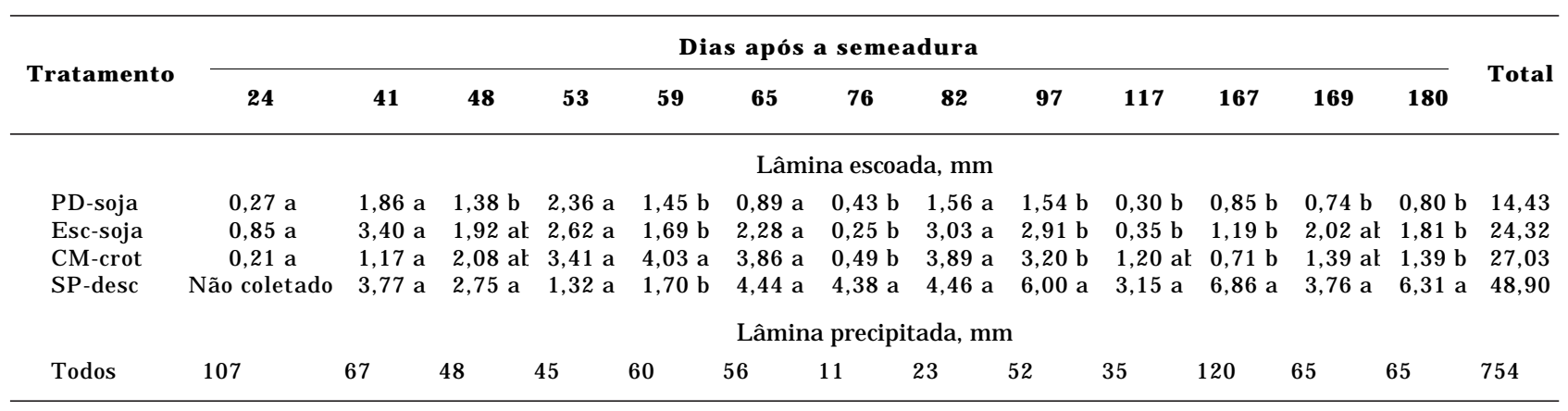


amostrais. Esses tratamentos, em geral também tiveram os maiores valores de infiltração de água sob chuva natural, $\mathrm{K}_{(\theta \mathrm{s})}$ e de cobertura do solo, evidenciando a importância da infiltração e o fluxo da água no armazenamento da água no solo. $\mathrm{Na}$ camada de 0,10 a 0,60 m, houve diferenças significativas, principalmente em dias de maior umidade do solo (dias 38, 44, 46, 50, 54, 69 e 114 a 133). No período de maior déficit hídrico, notou-se uma tendência de maior acúmulo de água no SPdesc, com diferença estatística somente no dia 93. Esse comportamento deveu-se à menor densidade de raízes e ausência de plantas nesse tratamento, diminuindo, assim, a demanda de água do solo.

A equação devan Genuchten foi ajustada à curva característica de água no solo. Todas as curvas apresentaram comportamento similar (Figura 8 e Quadro 4). Para a profundidade de 0,02 a 0,05 m, houve tendência em maior teor de água no solo para

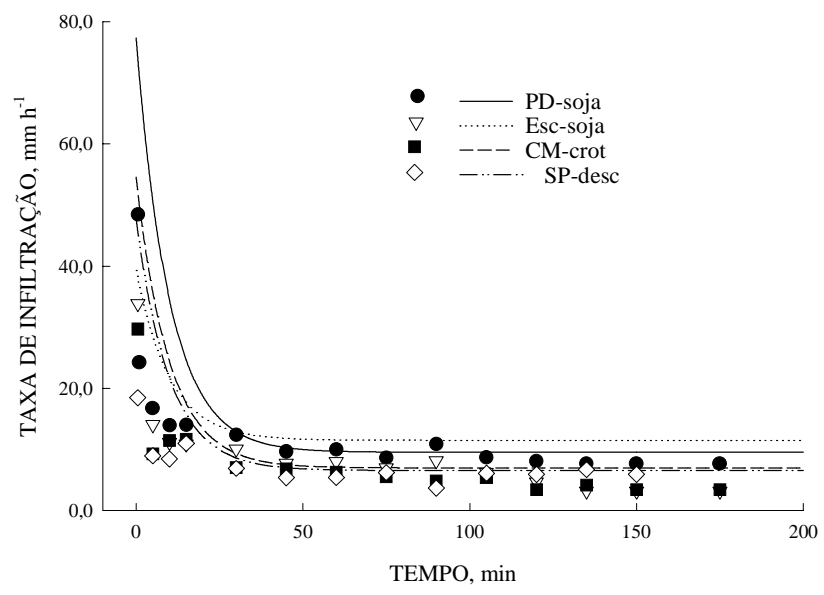

Figura 5. Infiltração de água no solo determinada pelo método dos anéis concêntricos e curva de infiltração calculada pela equação de Horton, em solo sob diferentes sistemas de manejo.

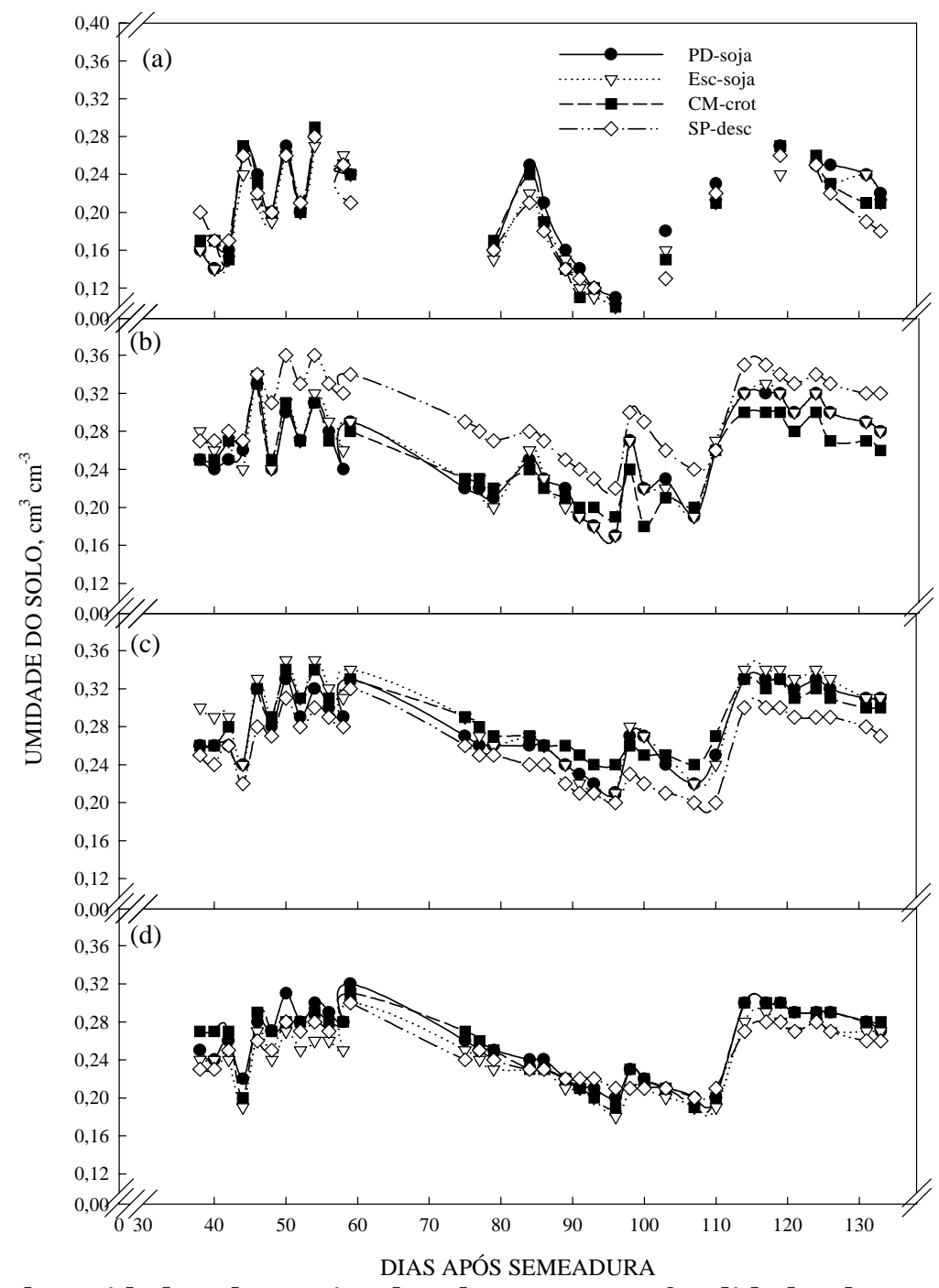

Figura 6. Variação da umidade volumétrica do solo para as profundidades de 0 a $0,10 \mathrm{~m}(\mathrm{a}) ; 0,10$ a $0,27 \mathrm{~m}$ (b); 0,27 a 0,43 m (c) e 0,43 a 0,60 m (d). 


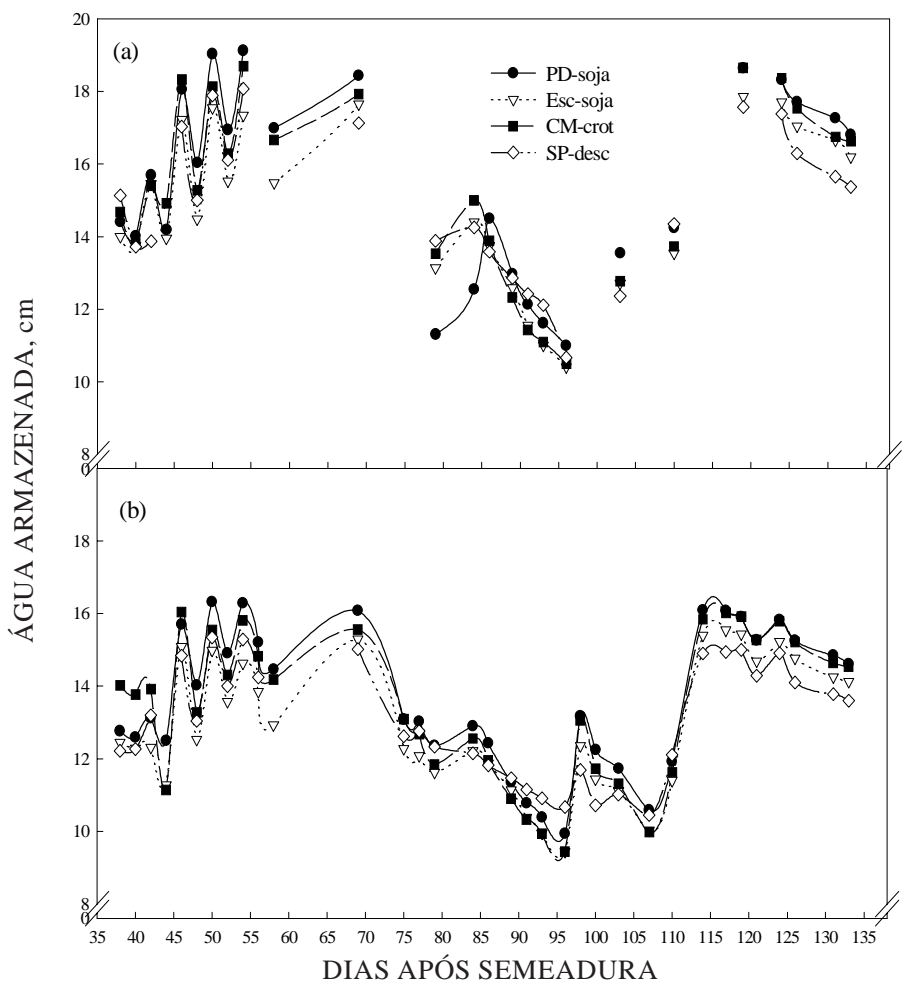

Figura 7. Lâmina média acumulada de água armazenada de 0-0,60 m (a) e de 0,10 a 0,60 m (b) em solo sob diferentes sistemas de manejo.

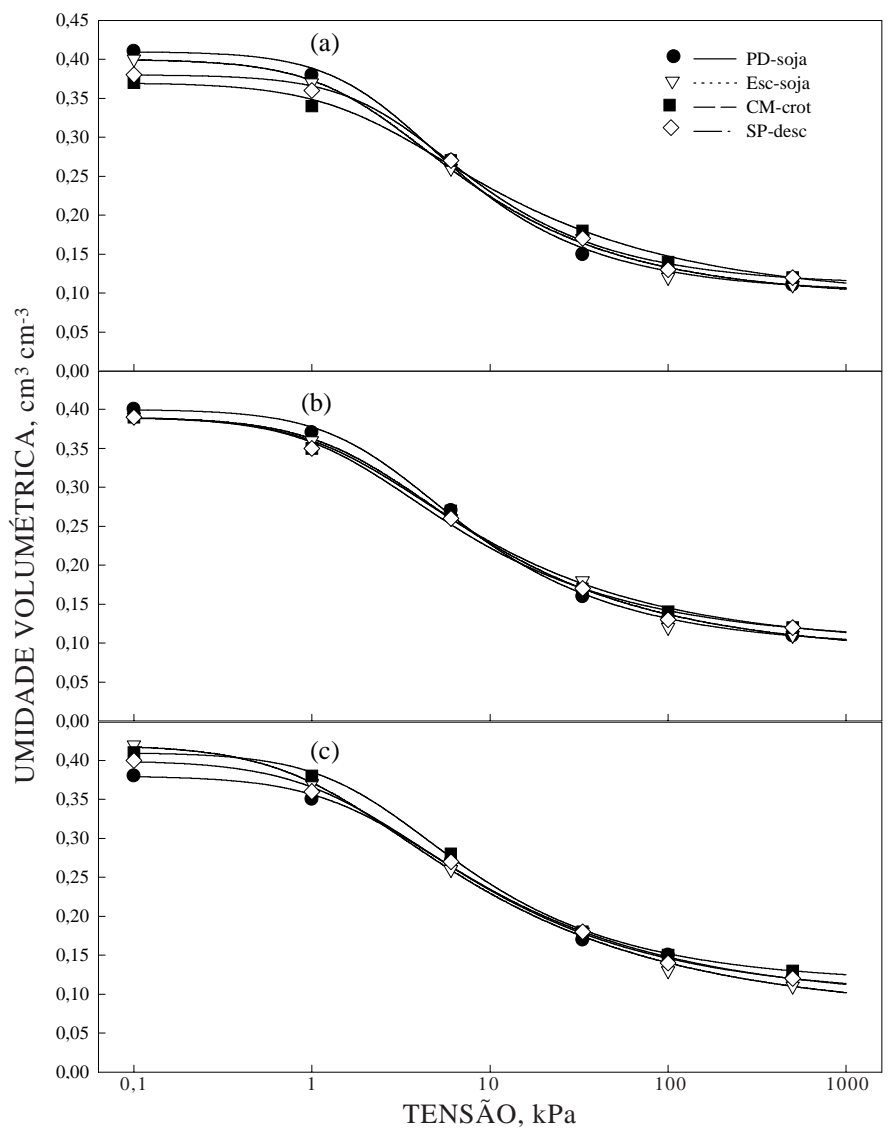

Figura 8. Curva característica de água no solo observada e calculada pela equação de Van Genuchten para as profundidade de 0,02 a 0,05 m (a), 0,12 to 0,15 m (b) e 0,35 a 0,38 m (c) em solo sob diferentes sistemas de manejo. 
Quadro 4. Valores dos parâmetros a, b e m e umidade $\theta$ r e $\theta \mathrm{s}$, calculados para a curva característica de água no solo pela equação de Van Genuchten, para solo sob diferentes sistemas de manejo

\begin{tabular}{|c|c|c|c|c|c|}
\hline Tratamento & a & $\mathbf{m}$ & b & $\theta \mathbf{r}$ & $\theta \mathbf{s}$ \\
\hline & $1 \mathrm{~m}^{-1}$ & & & $\ldots$ & 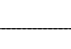 \\
\hline & \multicolumn{5}{|c|}{ Profundidade 0,02 a $0,05 \mathrm{~m}$} \\
\hline PD-soja & 0,0387 & 0,400 & 1,670 & 0,10 & 0,41 \\
\hline Esc-soja & 0,0463 & 0,350 & 1,540 & 0,09 & 0,40 \\
\hline CM-crot & 0,0439 & 0,300 & 1,430 & 0,09 & 0,37 \\
\hline \multirow[t]{2}{*}{ SP-desc } & 0,0315 & 0,400 & 1,660 & 0,11 & 0,38 \\
\hline & \multicolumn{5}{|c|}{ Profundidade 0,12 to $0,15 \mathrm{~m}$} \\
\hline PD-soja & 0,0402 & 0,360 & 1,570 & 0,10 & 0,40 \\
\hline Esc-soja & 0,0493 & 0,310 & 1,460 & 0,09 & 0,39 \\
\hline CM-crot & 0,0551 & 0,310 & 1,440 & 0,10 & 0,39 \\
\hline \multirow[t]{2}{*}{ SP-desc } & 0,0574 & 0,330 & 1,480 & 0,10 & 0,39 \\
\hline & \multicolumn{5}{|c|}{ Profundidade 0,35 to $0,38 \mathrm{~m}$} \\
\hline PD-soja & 0,0460 & 0,310 & 1,450 & 0,10 & 0,38 \\
\hline Esc-soja & 0,0804 & 0,270 & 1,380 & 0,07 & 0,42 \\
\hline CM-crot & 0,0446 & 0,350 & 1,540 & 0,11 & 0,41 \\
\hline SP-desc & 0,0612 & 0,290 & 1,410 & 0,09 & 0,40 \\
\hline
\end{tabular}

o solo saturado no tratamento Esc-soja e a menor com a CM-crot, considerando as diferenças na porosidade total entre os tratamentos. Para a determinação em tensões de 0,01 MPa, o comportamento foi muito similar às determinações com solo saturado. Para as demais profundidades, todos os tratamentos apresentaram comportamento similar.

\section{CONCLUSÕES}

1. A resistência mecânica à penetração (RP) foi máxima na camada de $0,075 \mathrm{~m}$, nos tratamentos sem preparo do solo, enquanto no sol o escarificado (E scsoja) a RP máxima ocorreu em maior profundidade $(0,175 \mathrm{~m})$. Contudo, a mobilização subsuperficial (escarificação) e a superficial (discagem e semeadura) do solo reduziram a densidade do solo (Ds).

2. O solo sob plantio direto de soja apresentou mais macroporos que CM-crot e SP-desc, na profundidade 0,02 a $0,05 \mathrm{~m}$, refletindo-se em maior $\mathrm{K}_{(\theta \mathrm{s})}$ e menor retenção de água no solo em situação de déficit hídrico.

3. Dentre as propriedades físico-mecânicas analisadas, a RP mostrou-se mais sensível em detectar a compactação do que a Ds e porosidades, especial mente para camadas de sol o pouco espessas.

4. A eficácia da ruptura da camada compactada do solo dependeu da propriedade hídrica ou mecânica do sol o usada como indicadora. Usando o indicador condutividade hidráulica do sol o saturado, a "escarificação biológica" (CM-crot) foi mais eficaz, em médio prazo, na ruptura da camada compactada e estabel ecimento de poros condutores de água do que a escarificação mecânica (Esc-soja) do solo. Em contrapartida, se o indicador for a RP e o interesse for a redução da resistência às raízes, o resultado é inverso.

\section{LITE RATURA CITADA}

ANKENY, M.D.; KASPAR, T.C. \& HORTON, R. Characterization of tillage and traffic effects on unconfined infiltration measurements. Soil Sci. Soc. Am. J ., 54:837-840, 1990.

AZOOZ, R.H. \& ARSHAD, M.A. Soil infiltration and hydraulic conductivity under long-term no-tillage and conventional tillage systems. Can. J. Soil Sci., 76:143-152, 1996.

BAGARELLO, V. I Ifluence of well preparation on field-saturated hydraulic conductivity measured with the Guelph permeameter. Geoderma, 80:169-180, 1997.

BRADFORD, J .M. Penetrability. In: KLUTE, A., ed. Methods of soil analysis. Part 1. Physical and mineralogical methods. 2.ed. Madison, American Society of Agronomy, 1986 ou 1986. 1188p.

CARVALHOJ r., O.S.; GASCÓ,J .M.; LOPEZ, F.G. \& REQUEJ O, A.S. Variabilidade espacial de algumas propriedades químicas e físicas de um solo submetido a diferentes sucessões de cultivo. R. Bras. Ci. Solo, 22:497-503, 1998.

COOKE, R.A.; MOSTAGHIMI, S. \& CAMPBELL, J .B. Assessment of methods for interpolating stead-stateinfiltrability. Trans. Am. Soc. Agric. Eng., 36:1333-1341, 1993.

CUBILLA, M.; REINERT, D.J .; AITA, C. \& REICHERT, J .M. Plantas de cobertura do solo: uma alternativa para aliviar a compactação em sistema plantio direto. R. Plantio Direto, 71:29-32, 2002. 
Da SILVA, A.P.; KAY, B.D. \& PERFECT, E. Characterization of the least limiting water range. Soil Sci. Soc. Am. J ., 58:1775-1781, 1994.

ELRICK, D.E.; REYNOLDS, W.D.; BAUMGARTNER, K.; TAN, K.A. \& BRADSHAW, K.L. In-situ measurements of hydraulic properties of soils using the Guel ph permeameter and the Guelph infiltrometer. In: INTERNATIONAL WORKSHOP ON LAND DRAINAGE, 3. Columbus, OH, 1987. Proceedings. OhioState University, 1987. p.G13-G23.

EMPRESA BRASILEIRA DE PESQUISA AGROPECUÁRIA EMBRAPA. Manual de métodos de análise de solo. 2.ed. Rio de J aneiro, 1997. 212p.

EMPRESA BRASILEIRA DE PESQUISA AGROPECUÁRIA EMBRAPA. Sistema brasileiro de classificação de solos. Brasília, 1999. 412p.

FERNANDES, B.; GALLOWAY, H.M.; BRONSON, R.D. \& MANNERING, J.V. Efeito de três sistemas de preparo do solo na densidade aparente, na porosidade total e na distribuição dos poros, em dois solos (Typic Argiaquoll e Typic Hapludaf). R. Bras. Ci. Solo, 7:329-333, 1983.

GENRO J UNIOR, S.A. Alteração da compactação do solo com o uso de rotação de culturas no sistema plantio direto. Santa Maria, Universidade Federal de Santa Maria, 2002. 90p. (Tese de Mestrado)

GIMENEZ, D.; ALLMARAS, R.R.; HUGGINS, D.R. \& NATER, E.A. Prediction of the saturated hydraulic conductivityporosity dependence using fractals. Soil Sci. Soc. Am. J., 61:1285-1292, 1997.

HÅKANSSON, I.; VOORHEES, W.B. \& RILEY, H. Vehicle and wheel factors influencing soil compaction and crop response in different traffic regimes. Soil Till. Res., 11:239-282, 1988.

HILLEL, D. Environmental soil physics. New York, Academic Press, 1998. 770p.

LETEY, J. Relationship between soil physical properties and crop productions. Adv. Soil Sci., 1:277-294, 1985.

MESSING, I. \& JARVIS, N.J. Temporal variation in the hydraulic conductivity of a tilled clay soil as measured by tension infiltrometers. J. Soil Sci., 44:11-24, 1993.

MUSY, A. \& SOUTTER, M. Physique du sol. Laussane, Presses Polytechniques et Universitaires Romandes, 1991. 335p.

PERROUX, K.M. \& WHITE, I. Designs of disc permeameters. Soil Sci. Soc. Am. J ., 52:1205-1215, 1988.

REYNOLDS, W.D. Fortran program to calculate saturated and unsaturated conductivity by Guel ph tension infiltrometer. Ontario, Agriculture and Agri-Food Canada, 1995.

REYNOLDS, W.D. Unsaturated hydraulic conductivity: field measurement. In: CARTER, M.R., ed., Soil sampling and methods analysis. Ottawa, Canadian Society of Soil Science, 1993. p.633-644.

REYNOLDS, W.D.; GREGORICH, E.G. \& CURNOE, W.E. Characterization of water transmission properties in tilled and untilled soils using tension infiltrometers. Soil Till. Res., 33:117-131, 1994.

SAS INSTITUTE. SAS User's guide: statistics. 5 ed. Cary, Sas Institute, 1985. 956p.
SAXON, K.E.; MCCOOL, D.K. \& KENNY, J.F. Tillage and residues impacts on infiltration. In: FOK, Y., ed. Infiltration principles and practices. Honolulu, Water Resources Research Center, 1988. p.509-513.

SCHÄFER, M.J.; REICHERT, J.M.; REINERT, D.J . \& CASSOL, E.A. Erosão em entressulcos em diferentes preparos e estados de consolidação do solo. R. Bras. Ci. Solo, 25:431441, 2001.

SECCO, D. Estados de compactação de dois latossolos e suas implicações no comportamento mecânico e na produtividade de culturas. Santa Maria, Universidade Federal de Santa Maria, 2003. 110p. (Tese de Doutorado)

SILVA, V.R. Variabilidade espacial da resistência do solo à penetração, intervalo hídrico ótimo e parâmetros físicohídricos influenciando a produção de culturas anuais. Santa Maria, Universidade Federal de Santa Maria, 2003. 180p. (Tese de Doutorado)

SILVA, V.R.; REINERT, D.J . \& REICHERT, J.M. Densidade do solo, atributos químicos e sistema radicular do milho afetados pelo pastejo e manejo do solo. R. Bras. Ci. Solo, 24:191-199, 2000a.

SILVA, V.R.; REINERT, D.J. \& REICHERT, J.M. Suscetibilidade à compactação de um L atossol o Vermel hoEscuro e de um Podzólico Vermelho-Amarelo. R. Bras. Ci. Solo, 24:239-249, 2000b.

SILVA, V.R.; REINERT, D.J . \& REICHERT, J .M. Resistência mecânica do sol o à penetração influenciada pelo tráfego de uma colhedora em dois sistemas de manejo do solo. Ci. Rural, 30:795-801, 2000c.

SOIL MOISTURE EQUIPMENT CORPORATION. Guelph permeameter model 2800 (user manual). Santa Barbara, Soilmoisture, 1991.

STRECK, C.A. Compactação do solo e seus efeitos no desenvolvimento e produtividade do feijoeiro e da soja. Santa Maria, Universidade Federal de Santa Maria, 2003. 105p. (Tese de Mestrado)

TAYLOR, H.M.; ROBERTSON, G.M. \& PARKER, J. Soil strength root penetration relations for medium to coarse textured soil materials. Soil Sci., 102:18-22, 1966.

TORMENA, C.A.; SILVA, A.P. \& LIBARDI, P.L. Caracterização do intervalo hídrico ótimo de um $L$ atossolo Roxo sob plantio direto. R. Bras. Ci. Solo, 22:573-581, 1998.

TSEGAYE, T. \& HILL, R.L. Intensive tillage effects on spatial variability of soil physical properties. Soil Sci., 163:143154, 1998.

van GENUCHTEN, M.T. A closed-form equation for predicting the hydraulic conductivity of unsaturated soils. Soil Sci. Soc. Am. J ., 44:318-333, 1980.

VOORHEES, W.B. Relative effectiveness of tillage and natural forces in alleviating wheel-induced soil compaction. Soil Sci. Soc. Am. J ., 47:129-133, 1983.

WANG, D.; YATES, S.R. \& ERNST, F.F. Determining soil hydraulic properties using tension infiltrometers, time domain reflectometry, and tensiometers. Soil Sci. Soc. Am. J ., 62:318-325, 1998.

WARRICK, A.W. \& NIELSEN, D.R. Spatial variability of soil physical properties in the field. In: HILLEL, D., ed. Applications of soil physics. New York, Academic Press, 1980. p.319-344. 